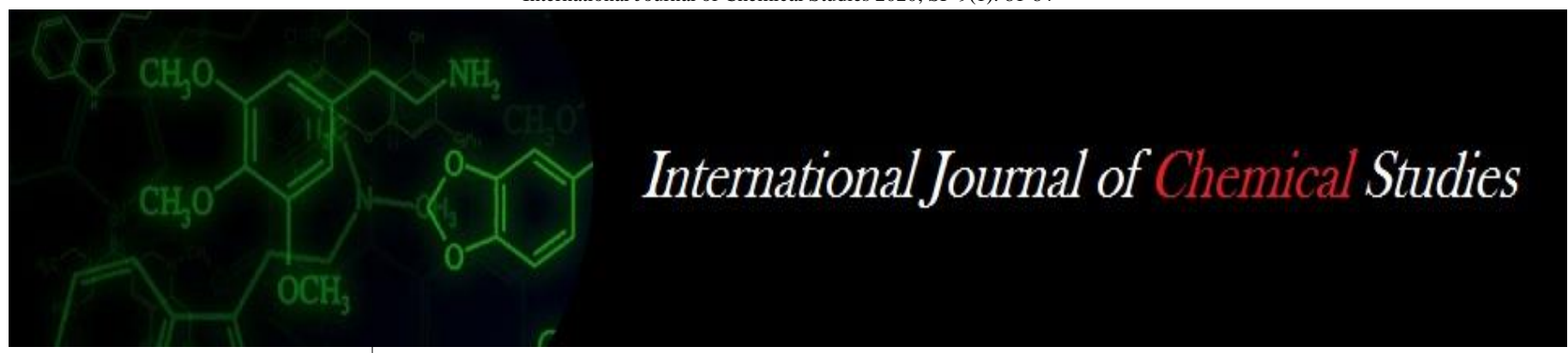

P-ISSN: 2349-8528

E-ISSN: 2321-4902

www.chemijournal.com

IJCS 2021; SP-9(1): 81-84

(C) 2021 IJCS

Received: 12-11-2020

Accepted: 17-12-2020

\section{DK Verma}

Department of Genetics and

Plant Breeding, ANDUAT,

Ayodhya, Uttar Pradesh, India

\section{SP Giri}

Crop Research Station, Masodha, ANDUAT, Ayodhya, Uttar

Pradesh, India

Saurabh Verma

Directorate of Extension,

ANDUAT, Kumarganj,

Ayodhya, Uttar Pradesh, India

RP Singh

Department of Agronomy,

ANDUAT, Ayodhya, Uttar

Pradesh, India

\section{SKS Rajpoot}

Crop Research Station, Masodha, ANDUAT, Ayodhya, Uttar

Pradesh, India

Pankaj Kumar Singh

Krishi Vigyan Kendra,

ANDUAT, Masodha, Ayodhya,

Uttar Pradesh, India

Shatrudhan Singh

Nandani Nager PG Collage,

Nababganj, Gonda, Uttar

Pradesh, India

N Parksh

Crop Research Station,

ANDUAT, Ghaghraghat,

Bahraich, Uttar Pradesh, India

Corresponding Author:

DK Verma

Department of Genetics and

Plant Breeding, ANDUAT,

Ayodhya, Uttar Pradesh, India

\section{Effect of nitrogen, phosphorus and potassium (NPK) application at various doses on yield of early transplanted rice}

\author{
DK Verma, SP Giri, Saurabh Verma, RP Singh, SKS Rajpoot, Pankaj \\ Kumar Singh, Shatrudhan Singh and N Parksh
}

DOI: https://doi.org/10.22271/chemi.2021.v9.i1b.11435

\begin{abstract}
Field experiment was carried out to assess the influence of various levels of NPK fertilizers (F1: 50-3020 \& F2: 100-60-40 kg/ha) on yield 5 new rice cultures namely IET 26767, IET 26803, IET 26477, IET 24914, IET 25713 and 4 national checks (Sahbhagi, Varalu, NDR 97 and Govind) and one local check (Shushk Smart) in split plot design with three replications at Crop Research Station, (ANDUAT), Masodha, Ayodhya. Results revealed that application of the highest grain yield was recorded with IET 25713 (4.87 t/ha). At higher level of RDF i.e. 150\% followed by IET 26477 (4.55 t/ha). The increase level of NPK increase up to (150\% RDF). The highest grain yield was recorded at $150 \% \mathrm{RDF} / \mathrm{ha}$ ( 3.84 t/ha). The lowest grain yield was recorded with recommended level of RDF (100\%/ha) (3.69 t/ha). Shabhagi dhan recorded lower mean grain yield of RDF and higher level of RDF.
\end{abstract}

Keywords: Growth, productivity, fertilizer recommendation, yield rice

\section{Introduction}

A large proportion of world's population utilizes rice (Oryza sativa L.) as staple food (Islam et al., 2010; Atera et al., 2011) ${ }^{[2,6]}$. On global scale the cultivation of rice is carried out on about 148 million hectares with production of 710 million tons (FAO, 2011) ${ }^{[4]}$. Out of this almost $90 \%$ rice production and consumption takes place in Asian countries (Islam et al., 2010) ${ }^{[6]}$. In Asia, the largest rice producing countries include China, India, Indonesia, Bangladesh and Pakistan $\left(\right.$ FAO, 2011) ${ }^{[4]}$. A share of $41.39 \%$ in total food grain produced and $55 \%$ of cereals produced in the country, contributing 20-25\% to Agricultural GDP (Anonymous, 2016) ${ }^{[1]}$. In India, rice is grown on nearly $43.49 \mathrm{~m}$ ha with total production of $104.4 \mathrm{~m} \mathrm{t}$ and productivity of $2400 \mathrm{~kg} / \mathrm{ha}$ (Anonymous, 2016) ${ }^{[1]}$. It serves as the staple food for more than half of the globe's population (Khan et al, 2013) ${ }^{[7]}$. Rice is the third highest produced cereal after wheat and maize (FAOSTAT, 2012) ${ }^{[5]}$.

NPK is the key element in the production of rice and gives by far the largest response. It is the most essential element in determining the yield potential of rice and nitrogenous fertilizer is one of the major inputs to rice production (Mae T, 1997) ${ }^{[9]}$. However, recovery of applied nitrogen in rice is very low owing to various losses. Optimization of applied nitrogen at critical growth stages, coinciding with the period of efficient utilization is essential to meet the nitrogen requirement of crop throughout the growing season (Pandey S et al., 2002) ${ }^{[9]}$. Almost every farmer has the tendency to apply costly $\mathrm{N}$ fertilizer excess to get a desirable yield of Aman rice (Saleque MA et al. 2004) ${ }^{[10]}$, but the imbalance use of $\mathrm{N}$ fertilizer causes harm to the crop and decreases grain yield. It is also a fact that improper use of nitrogenous fertilizer, instead of giving yield advantage, may reduce the same. Nitrogen management is an important aspect for obtaining good yield of rice. Optimum dose and schedule of fertilizer application is necessary to achieve higher yields, minimize lodging and damage from insect pests (DRR, 2013) ${ }^{[3]}$. (Sangeetha and Balakrishnan, 2013) ${ }^{[11]}$ reported that lower grain yield of rice obtained with absolute control which did not receive organic manures and recommended NPK addition. Nitrogen fertilization and proper time of its application is the major agronomic practice that affects the yield and quality of rice crop (Lampayan RM et al., 2010) ${ }^{[8]}$. Different varieties may have varying responses to $\mathrm{N}$-fertilizer depending on their agronomic traits. Now 
a days the identification and release of high yielding very early rice varieties, it becomes imperative to make a comparative assessment of the growth studies and their influence on grain yield under different nutrient combination.

\section{Materials and Methods}

A experiment was carried out to assess the influence of various level of NPK fertilizers (F1: 50-30-20 \& F2: 100-60$40 \mathrm{~kg} / \mathrm{ha}$ ) on yield of five new rice cultures namely IET 26767, IET 26803, IET 26477, IET 24914, IET 25713 and 4 national checks (Sahbhagi, Varalu, NDR 97 and Govind) and one local check (Shushk Smart) in split plot design with three replications under field condition at Crop Research Station, (ANDUAT), Masodha, Ayodhya, which is situated at 26.47 ${ }^{0} \mathrm{~N}$ (latitude), $82.12{ }^{0} \mathrm{E}$ (longitude) and at $113 \mathrm{~m}$ (altitude). Soil of the experimental field is sandy loam with $\mathrm{pH} 7.2$, organic carbon $0.40 \%$, Nitrogen $200 \mathrm{~kg} / \mathrm{ha}, \mathrm{P} 2 \mathrm{O} 524 \mathrm{~kg} / \mathrm{ha}$ and $\mathrm{K} 2 \mathrm{O} 234 \mathrm{~kg} / \mathrm{ha}$. Crop nursery was grown in raised beds and twenty one days old seedlings were transplanted in the $2^{\text {nd }}$ week of July, two hills of seedlings were planted in each pot with planting depth and distance of $15 \mathrm{~cm}$ and $20 \mathrm{~cm}$, respectively. Cultural practices such as weeding, irrigation, pest control etc. were done when necessary. Regular flood irrigation was applied in pots throughout the vegetative stages and left completely dried upon reaching the grain filling stages. Single fertilizer namely urea, single super phosphate (SSP) and muriate of potash (MOP) fertilizer were used as source of nitrogen, phosphorus and potassium, respectively. Split application of NPK fertilizer (Sariam, 2008) was applied based on the rice varieties growth phase, day after transplanting due to their different maturity period. Urea fertilizer was applied at split application of $50 \%$ and $50 \%$ during vegetative and heading phase, respectively.

Parameters measured for physiological characteristics of rice were: (i) grain yield t/ha, (ii) panicle no per sqm, (iii) panicle weight per panicle (g), (iv) test weight (g) and (vii) days to $50 \%$ flowering. Harvesting were carried out when $90 \%$ of the grains had turned hard, clear and free from greenish tint (Panda, 2010). The data on grain yield of each plot were recorded separately by threshing the harvested of rice cultures on tarpaulin followed by proper sun drying and winnowing. Data collected were statistically analysed using two-ways analysis of variance (ANOVA), and Duncan's new multiple range test (DMRT) was employed to determine the mean differences between the treatments using the statistical package.

\section{Results and Discussion}

There were significant differences among the potential very early rice genotypes/varieties in plant growth, yield attributes and grain yield. All yield attributing characters (number of panicle $/ \mathrm{m} 2$ and panicle weight) were remained differed with different varieties. The data presented in table-1 and figure 1 clearly revealed that the level of NPK increase grain yield significantly. Among the treatment of $100 \%$ recommended dose of fertilizer 50:30:20 NPK, genotypes IET IET 25713 recorded maximum grain yield $(4.52 \mathrm{t} / \mathrm{ha})$ followed by IET $25713(4.51 \mathrm{t} / \mathrm{ha})$. The treatment of $150 \%$ recommended dose of fertilizer 100:60:40 NPK IET 25713 recorded maximum grain yield (4.87 t/ha) followed by IET 26477 (4.56 t/ha). Increase the grain yield of $150 \%$ recommended dose of fertilizer IET 25713 (7.98) followed by IET 26767 (5.45\%). The lower yield t/ha was $100 \%$ RDF of Sahbhagidhan 2.90 t/ha and $150 \%$ RDF grain yield was recorded Sahbhagidhan $3.13 \mathrm{t} / \mathrm{ha}$.

Among the genotypes/varieties, IET 26767 (early rice genotype) recorded maximum number of panicles $\mathrm{m}-2$ (255 \& 266), maximum panicle weight of IET 26477 (3.56 \& $4.13 \mathrm{~g}$ ) and finally recorded highest test weight IET 26477 (23.97 \& $26.23 \mathrm{~g}$ ).

From the present study, it may be concluded that among the potential early rice genotypes/varieties IET 22020 proved most impressive by recording the highest grain yield and IET 27513 exerted second promising early rice genotype under irrigated mid early situation of Eastern Uttar Pradesh. IET 27513 has the potential to be an alternative/replacement as early rice genotype for $150 \%$ recommended NPK.

Table 1: Grain yield and ancillary characters of ETP rice at different levels of NPK fertilizer doses

\begin{tabular}{|c|c|c|c|c|c|c|c|c|c|c|c|c|c|c|c|}
\hline \multirow[b]{2}{*}{ Cultivar } & \multicolumn{2}{|c|}{$\begin{array}{c}\text { Grain yield } \\
\text { t/ha }\end{array}$} & \multirow[t]{2}{*}{\begin{tabular}{|c|}
$\%$ \\
increase \\
over F1 \\
\end{tabular}} & \multicolumn{2}{|c|}{$\begin{array}{l}\text { Panicle } \\
\text { No./m2 }\end{array}$} & \multirow[t]{2}{*}{$\begin{array}{c}\% \text { increase } \\
\text { over F1 }\end{array}$} & \multicolumn{2}{|c|}{$\begin{array}{c}\text { Panicle } \\
\text { weight (g) }\end{array}$} & \multirow[t]{2}{*}{$\begin{array}{c}\% \text { increase } \\
\text { over F1 }\end{array}$} & \multicolumn{2}{|c|}{$\begin{array}{c}\text { Test weight } \\
\text { (g) }\end{array}$} & \multirow[t]{2}{*}{$\begin{array}{c}\% \text { increase } \\
\text { over F1 }\end{array}$} & \multicolumn{2}{|c|}{$\begin{array}{c}\text { Days to 50\% } \\
\text { flowering }\end{array}$} & \multirow[t]{2}{*}{\begin{tabular}{|c|}
$\%$ \\
Increase \\
over F1 \\
\end{tabular}} \\
\hline & F1 & $\mathrm{F} 2$ & & F1 & F2 & & F1 & F2 & & F1 & F2 & & F1 & $\mathrm{F} 2$ & \\
\hline IET 26767 & 4.22 & 4.45 & 5.45 & 256 & 266 & 3.91 & 3.29 & 3.24 & -1.52 & 23.77 & 25.67 & 7.99 & 85 & 85 & 0.00 \\
\hline IET 26477 & 4.52 & 4.56 & 0.88 & 253 & 267 & 5.53 & 3.56 & 4.13 & 16.01 & 23.97 & 26.23 & 9.43 & 84 & 87 & 3.57 \\
\hline IET 24914 & 4.15 & 4.08 & -1.69 & 255 & 267 & 4.71 & 3.23 & 3.65 & 13.00 & 22.60 & 23.47 & 3.85 & 85 & 86 & 1.18 \\
\hline IET 25713 & 4.51 & 4.87 & 7.98 & 255 & 264 & 3.53 & 3.31 & 3.09 & -6.65 & 23.40 & 24.43 & 4.40 & 85 & 86 & 1.18 \\
\hline NC-Sahbhagidhan & 2.90 & 3.13 & 7.93 & 257 & 263 & 2.33 & 2.90 & 3.00 & 3.45 & 20.40 & 22.40 & 9.80 & 81 & 81 & 0.00 \\
\hline ZC-Govind (NW) & 3.16 & 3.43 & 8.54 & 253 & 268 & 5.93 & 2.82 & 3.10 & 9.93 & 21.43 & 24.57 & 14.65 & 79 & 77 & -2.53 \\
\hline Varalu & 3.33 & 3.39 & 1.80 & 257 & 257 & 0.00 & 2.65 & 2.78 & 4.91 & 22.33 & 23.77 & 6.45 & 83 & 83 & 0.00 \\
\hline $\begin{array}{c}\text { Local Check Susk } \\
\text { samrat }\end{array}$ & 3.26 & 3.92 & 20.25 & 255 & 266 & 4.31 & 3.62 & 3.53 & -2.49 & 23.63 & 25.60 & 8.34 & 81 & 85 & 4.94 \\
\hline Interaction $\mathrm{F}$ at same $\mathrm{V}$ & \multicolumn{2}{|c|}{ NS } & & \multicolumn{2}{|c|}{3.12} & & \multicolumn{2}{|c|}{ NS } & & \multicolumn{2}{|c|}{0.57} & & \multicolumn{2}{|c|}{ NS } & \\
\hline $\mathrm{V}$ at same $\mathrm{F}$ & \multicolumn{2}{|c|}{ NS } & & \multicolumn{2}{|c|}{3.29} & & \multicolumn{2}{|c|}{ NS } & & \multicolumn{2}{|c|}{0.54} & & \multicolumn{2}{|c|}{ NS } & \\
\hline F1 & \multicolumn{2}{|c|}{3.76} & & \multicolumn{2}{|c|}{255} & & \multicolumn{2}{|c|}{3.17} & & \multicolumn{2}{|c|}{22.69} & & \multicolumn{2}{|c|}{83} & \\
\hline F2 & \multicolumn{2}{|c|}{3.98} & & \multicolumn{2}{|c|}{265} & & \multicolumn{2}{|c|}{3.30} & & \multicolumn{2}{|c|}{24.52} & & \multicolumn{2}{|c|}{84} & \\
\hline C.D. (0.05) & \multicolumn{2}{|c|}{0.19} & & \multicolumn{2}{|c|}{1.94} & & $\mathrm{~N}$ & & & & .11 & & & & \\
\hline C.V. (\%) & & 88 & & & & & 18. & & & & .37 & & & & \\
\hline
\end{tabular}




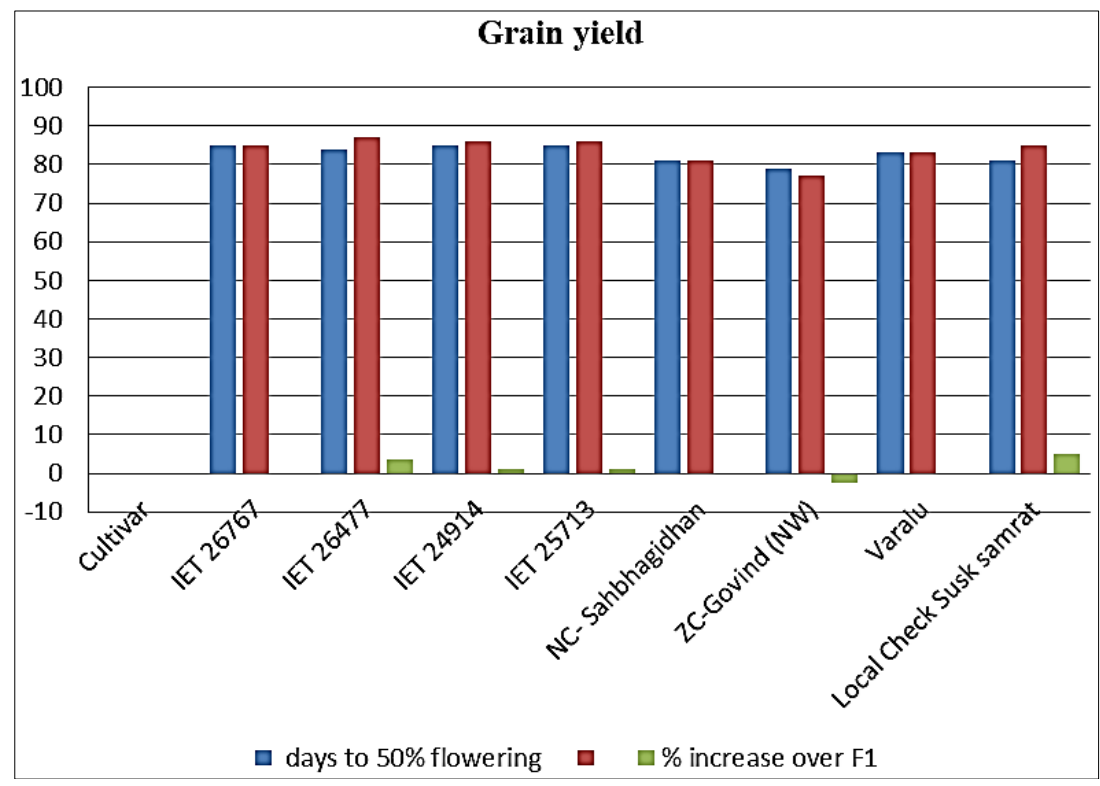

Fig 1: Grain yield and increase \% over F1

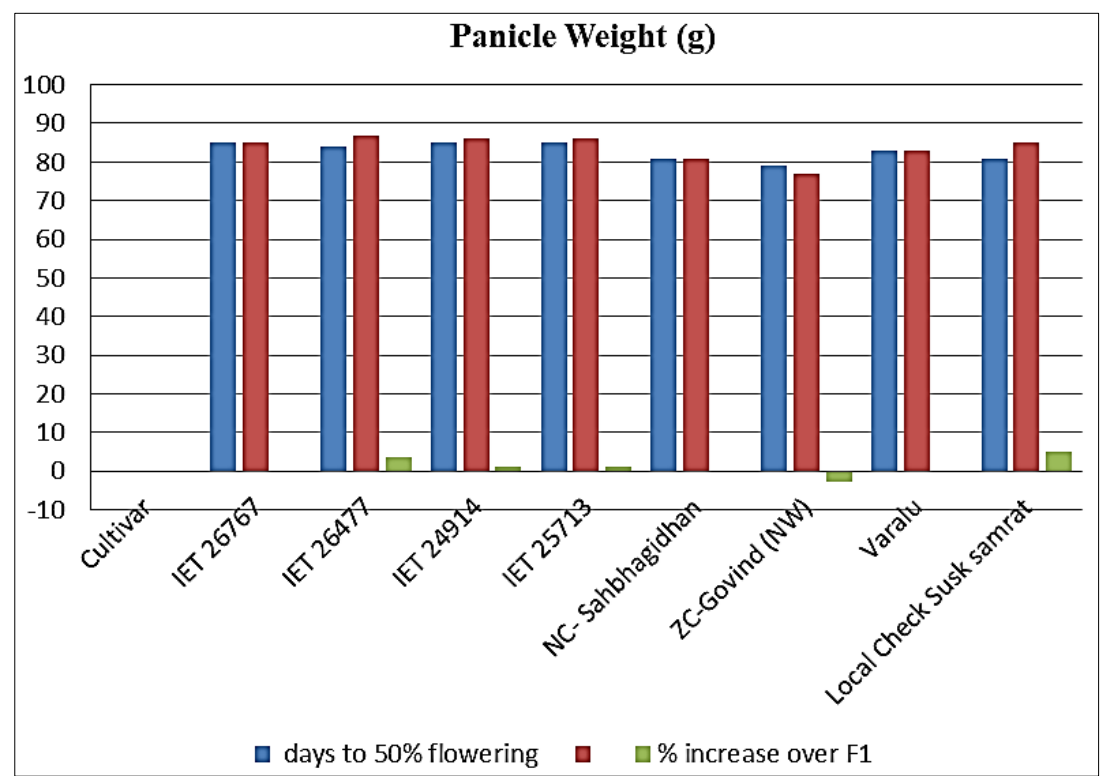

Fig 2: Panicle weight $\mathrm{g}$ of ETP rice

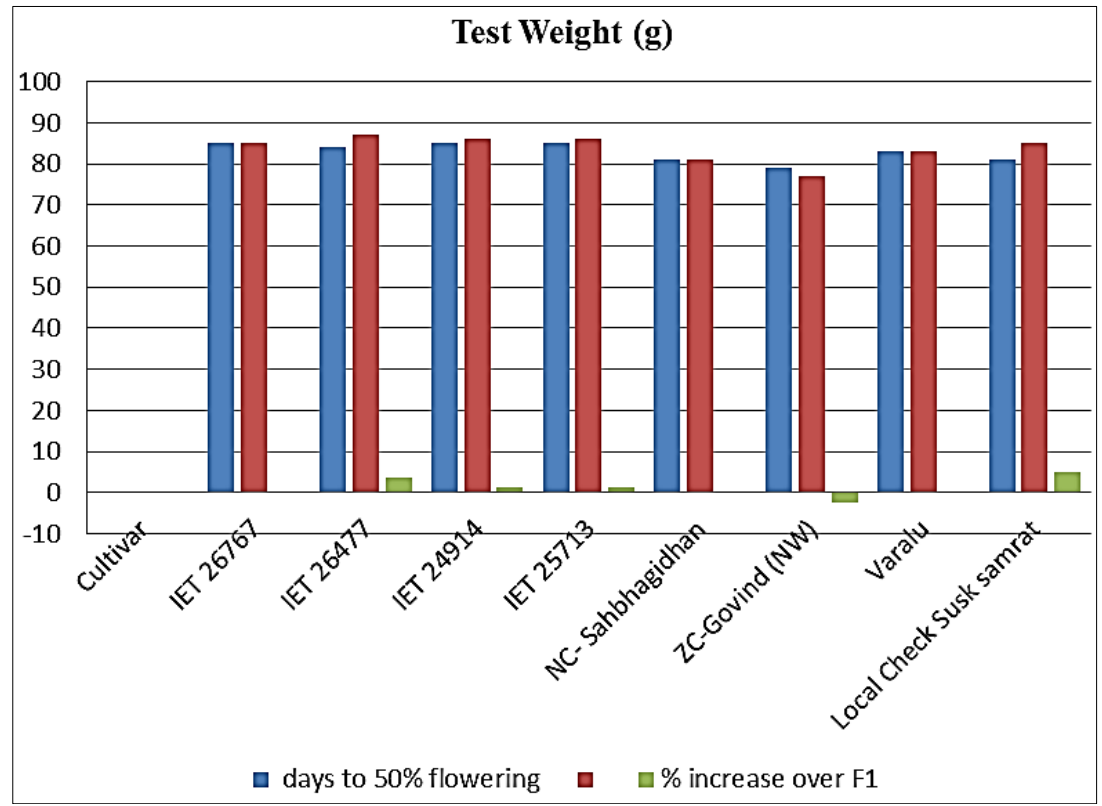

Fig 3: Test weight (g) of ETP rice 


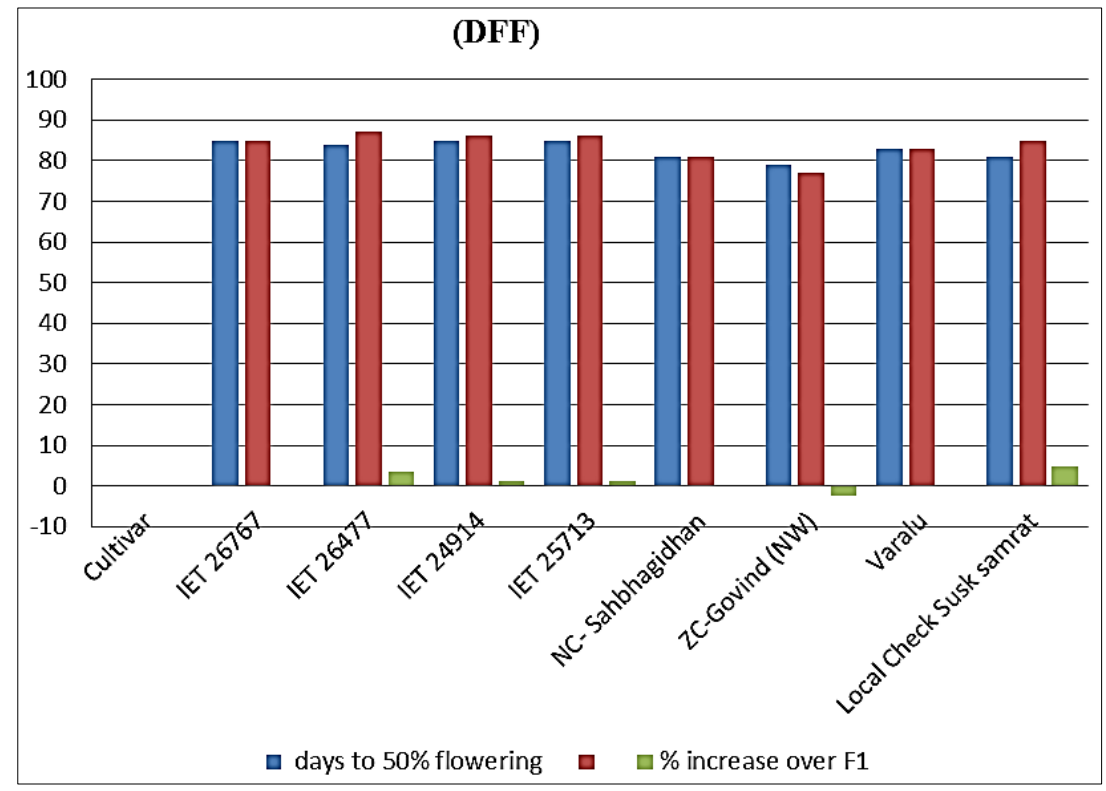

Fig 4: Days to 50\% flowering of ETP rice

\section{References}

1. Anonymous. India stat base 2016 . https://www.india.stat.com Anonymous.

2. Atera EA, Onyango JC, Azumal T, Asanuma S, Itoh K. Field evaluation of selected NERICA rice cultivars in Western Kenya. Afr J Agric Res 2011;6:60-66.

3. DRR (Directorate of Rice Research). Water saving technologies in rice. DRR Technical Bulletin No.75/2013 2013, P40-45.

4. FAO. Trends of rice paddy production: monitoring the market 2011.

http://www.fao.orglesclfr\15\70 \highlight_71html.

5. FAOSTAT. Food and Agricultural Organization of the United Nations, Rome Italy, Statistical Data Base 2012. http://faostat.fao.org

6. Islam MS, Peng S, Visperas RM, Sultan M, Altaf SM, Julfiquar AW. Comparative study on yield and yield attributes of hybrid, inbred, and NPT rice genotypes in a tropical Irrigated ecosystem. Ban J Agric Res 2010;35:343-353.

7. Khan AS, M Imran, M Ashfaq. Estimation of Genetic Variability and Correlation for Grain Yield Components in Rice (Oryza sativa L.). American-European J Agric Environ Sci 2013;6:585-590.

8. Lampayan RM, Bouman BAM, Dios JLD, Espirity AJ, Soriano JB et al. Yield if aerobic rice in rainfed lowlands of the Philippines as affected by nitrogen management and row spacing. Field Crop Res 2010;116(1-2):165-174.

9. Mae T. Physiological nitrogen efficiency in rice: Nitrogen utilization, photosynthesis and yield potential. Plant Soil 196(2):201- 210. Pandey S, Mortimer M, Wade L, Tung TP, Lopez K et al. (2002) Direct seeding: Research strategies and opportunities. IRRI, Los Banos, Philippines 1997, P383.

10. Saleque MA, Naher UA, Islan A, Patahn ABMU, Hossain ATMS et al. Inorganic and organic phosphorous fertilizer effects on the phosphorus fractionation in wetland rice soils. Soil Sci Soc Am J 2004;68:1635-1644.

11. Sangeetha SP, Balakrishnan A. Effect of organically supplemented $\mathrm{N}$ on yield of rice (Oryza sativa L.). Journal of Crop and Weed 2011;7(1):86-88. 